\title{
Analysis of Computer-Generated Drug Label Errors in a Tertiary Care Hospital
}

\author{
Ahmed AbdulRahim Abusham*, Hamida Rashid AlRawahi \\ Department of Clinical Pharmacy, University of Nizwa College of Pharmacy and Nursing, Nizwa-PO Box 33 PC 616, OMAN.
}

\section{Received: 02 June 2018; \\ Accepted: 28 August 2018 \\ *Correspondence to: \\ Dr. Abusham AA, Ph.D,}

Assistant Professor - Clinical Pharmacy,

University of Nizwa College of Pharmacy and Nursing, Nizwa - PO Box 33 PC 616, OMAN. Email:abusham@unizwa.edu.om

Copyright: (C) the author(s),publisher and licensee Indian Academy of Pharmacists. This is an open-access article distributed under the terms of the Creative Commons Attribution Non-Commercial License, which permits unrestricted non-commercial use, distribution, and reproduction in any medium, provided the original work is properly cited.

\begin{abstract}
Background: Electronic Systems and recommendations have been developed to facilitate the medication dispensing process, but on the other hand, they may generate dispensing errors themselves. This study is meant to assess the computer-generated drug label errors (CGDLEs). Objective: The main objective of this study is to identify the pattern and assess the significance of CGDLEs in a tertiary care hospital. Methodology: A total of 292 computer-generated drug label errors involving 169 patients and 61 medications were researched over 3 months (from January 1, 2017, to Mar 30, 2017) in a 500-bed tertiary care hospital. Collected data included patient demographics, type of error, error-related medications, time taken to resolve the error, station where error was identified and the clinical significance of the error. Analyses were conducted using STATA ${ }^{\circledR}$ v14.2 with descriptive and inferential statistics. Results: Thirty eight percent of the detected CGDLEs were considered major. Patients age ranged between 0.2 to 97 years $(M \pm S D=36.4 \pm 24.3)$. Errors within the age group of 0.2 to 2 years represented $7.89 \%$ of the total errors. Errors within the age group of 61 years and above represented $21.91 \%$ of the total errors. Duration of therapy represents $34.59 \%$ of the total errors, followed by instructions for use $(29.45 \%)$ and drug dose (19.86\%). The major CGDLEs commonly include medications like tacrolimus (17.69\%), methotrexate (16.81\%) and ciclosporin (15.40\%). Conclusion: $\mathrm{A}$ considerable proportion of all CGDLEs was observed. Many of these errors were serious and could directly affect the wellbeing of patients. Fortunately, these errors were captured before reaching patients. Urgent assessment of the system that generates such labels is required.
\end{abstract}

Key words: Computer-generated drug label, Dispensing errors, Medication errors.

\section{INTRODUCTION}

Computer-generated drug label (CGDL) is the printed material comprising essential drug and patient information and relevant instruction for use to help appropriate and safe use of medication. The design and content of CGDL can impose a significant effect on the way medications should be used. Labels are intended to clearly identify a specific patient and guide him on appropriate use of his medication. ${ }^{[1]}$

Studies have proved that technologies have a role in reducing medication errors. ${ }^{[2-3]}$ However, technologies may facilitate new medication errors. Researcher Samaranayake and his colleagues evaluate the role of computerized physician order entry systems (CPOE) on 1538 medication incidents and reported that $17.1 \%$ of all incidents were technology-related, where $6.8 \%$ were related to computer-aided drug label generation. The direct causes for technology associated errors included user-PC poor interface (68.1\%), rule violations $(22.1 \%)$, technical defects $(1.9 \%)$ and others. Also, they reported that $11.4 \%$ of technology-related incidents were detected after drug administered and $6.1 \%$ of them actually caused harm to patient. ${ }^{[4]}$ Walsh et al. using a newer version of the same CPOE system, found only 4 types of errors. ${ }^{[5]}$ Koppel et al. conducted a large study to assess the correlation between technology and medication errors and found few instances where errors can occur despite of technology, demonstrating that errors may have been eliminated by excellence in technology ${ }^{[6]}$ However, unintended medication errors still occur despite improvements in technology. It is quite possible that newer technologies will come up with new types of CGDLEs; therefore, technology-related errors must be evaluated on regular basis.
The culture of safety is promoted among all Omani public hospitals and as a strategy to improve quality of patient care, the Hospital Information System (HIS) in the royal hospital has been used to manage the CGDLs as part of medication dispensing process. A bilingual (English + Arabic) label generated by this system usually contains patient's particulars, medication name, dosage form, strength, dose, frequency, duration and cautionary instructions, if any.

\section{MATERIALS AND METHODS Setting}

This study was undertaken in the Pharmacy Department of the Royal Hospital, a government-funded tertiary care, 500 beds, public hospital in Oman. The hospital information management system (HIMS) was introduced in this hospital in 2007 and pharmacists have been using this system to facilitate prescription screening and medication dispensing processes, including computer-generated drug labels. We define Computer-generated drug label error (CGDLE) as any error related to a computer- generated label used in the medication dispensing process. On average, 400 prescriptions were received from different departments/clinics daily including inpatient discharge prescriptions.

\section{Data collection}

The study was carried out on outpatient and discharge prescriptions during normal working hours $(7: 30 \mathrm{am}$ to $2: 30 \mathrm{pm})$. Data collection was carried out in a three-month period from January 1, 2017, to Mar 30, 2017. A total of 292 errors involving169 patients and 61 medications were identified and collected 


\section{Abusham and Alrawahi, et al.: Computer-Generated Drug-Label Errors}

using data collection form (DCF). The contents of the DCF included patient demographics, type of error, error-related medication, time taken to resolve the error, station where error was discovered and the clinical significance of the error. The study was approved by the University of Nizwa research committee and the Royal Hospital authorities.

\section{Error review and classification}

The CGDLEs were reviewed and classified by a panel of three senior clinical pharmacists. The clinical significance of error was defined as major, moderate, mild and none after a previously described method for risk matrix definitions and their impact on patients. ${ }^{[7]}$ (Table 1) The panel assessed the potential for patient harm of each error. As per Nanji et al. potential error was considered major if the event could cause symptoms that lead to patient death if not treated; examples include patient fatality or potential end organ damage, cardiac arrest, anaphylaxis and respiratory failure. A potential error was considered moderate if the event could cause symptoms that are associated with a serious but non-life-threatening level of risk; example include harm that needs hospitalization or emergency treatment, symptomatic bradycardia, dizziness and syncope. A potential error was termed mild if the event could cause symptoms that, while harmful to the patient, pose little or no threat to the patient's life function; example include that does not need hospitalization or emergency treatment like rash, mild diarrhea, nausea and headache. In the 'none' class, there is error but no obvious harm to the patient. ${ }^{[8]}$

\section{Outcomes}

Our primary outcomes were the incidence of computer-generated drug label errors and the related potential for patient harm. Our secondary outcome was the rate of CGLEs by error pattern. Error patterns included drug dose, frequency, duration, dosage form and patient instruction for use.

\section{Data analysis}

Statistical analyses were conducted using STATA version 14.2 (Stata Corporation, 2015; College Station, TX, USA). For continuous variables, means and standard deviations were reported. For categorical variables, frequencies and percentages were reported. We applied Chi-square tests to examine bivariate associations between errors and recoded age groups. Medications commonly associated with potential CGDLEs were presented as counts with percentages.

\section{RESULTS}

The age of patients affected by CGDLs ranged between 0.2 to 97 years $(\mathrm{M} \pm \mathrm{SD}=36.4 \pm 24.3)$. Errors within the age group of 0.2 to 2 years represented $7.89 \%$ of the total errors where $1.37 \%$ of them considered major. Errors affecting the age group of 61 years and above represented $21.91 \%$ of the total errors where $8.90 \%$ of these errors considered major.

Figure 1 shows the patterns of CGDLEs (duration of therapy, Instructions for use, drug dose, frequency of drug doe, etc) and the commonly involved medications in each pattern where duration of therapy represented 34.59\% and commonly involved medications include methotrexate injection/tablets (36.63\%), adalimumab injection, erythropoietin injection and etanercept injection. Instructions for use comprised $29.45 \%$ of the errors and include medications like adalimumab injection (18.60\%), methotrexate injection/ tablet, ciclosporin capsule and syrup, tacrolimus capsule, erythropoietin injection and sodium $0.9 \%$ injection. Errors affecting drug dose represented $19.86 \%$ of the total errors and the commonly involved medications include ciclosporin capsule and tacrolimus capsule $(12.06 \%$ each). The frequency of drug dose errors represented $10.96 \%$ and the commonly involved medications include Budesonide+ formoterol (21.87\%), in addition to ciclosporin capsule, dornase for inhalation and thyroxine tablets.

Table 4 shows medications commonly affected by CGDLEs stratified by the level of clinical significance of error. The major level represented 38.69\% of the total errors. Medications commonly involved include tacrolimus capsule (17.69\%), Methotrexate capsule/injection (16.81\%) and Ciclosporin capsule $(15.40 \%)$. The moderate level represented $28.77 \%$ of the total errors and medications involved include budesonide+ formoterol $(11.90 \%)$ and cotrimoxazole tab/suspension $(8.33 \%)$. The minor level of clinical significance represented $25.00 \%$ and included medications like folic acid tablets $(15.06 \%)$ and vitamin D3 capsule (13.69\%). Major errors associated with the age group of $\leq 2$ years included medications like erythropoietin injection, sodium chloride $0.9 \%$ injection and pancreatic granules. Major errors associated with age group of $>60$ years included medications like tacrolimus capsule, etanercept for inhalation and ciclosporin injection/ capsule/solution.

As we can see in Table 4, most of the medications associated with CGDLEs were under the class of immunosuppressants and/or cytotoxics. This may indicate the seriousness of such errors as most, if not all of these medications could impose a potential life threating adverse effect on patients, especially pediatric and geriatric groups.

Ninety five percent of the identified CGDLEs were captured in station $\mathrm{B}$ where items are prepared and labeled. The rest was captured in station $\mathrm{C}$ during delivery of medication to the patient. The mean time taken to correct an error was 1.68 minutes $(\mathrm{M} \pm \mathrm{SD}=1.68 \pm 1.23)$ and the maximum time was 9 min.

\section{DISCUSSION}

We assessed the pattern, content and clinical significance of 292 computergenerated drug label errors (CGDLEs) involving 61 medications and 169 patients in a tertiary care hospital. Thirty eight percent of the detected GCDLEs were considered as major errors. Shrank et al. found that medication labels poorly designed accounted for approximately $33 \%$ of errors investigated by the US Pharmacopoeia and in many cases, it was due to confusion caused by the label. ${ }^{[9]}$ Furthermore, it is common that patients may receive no verbal instructions from healthcare providers except the instructions on the label and this highlights the importance of the welldesigned medication label. ${ }^{[10]}$ Labeling improvements guidelines have been presented in two recent Institute of Medicine (IOM) reports focusing on medication safety. According to IOM reports, poor labeling is an important source of medication/dispensing errors and variability in drug labeling can negatively affect a patient's comprehension of instructions. ${ }^{[11-12]}$

In our study female gender represented $71.6 \%$ of the study population. The age of patients ranged between 0.2 to 97 years $(\mathrm{M} \pm \mathrm{SD}=36.4 \pm 24.3)$ (Table 2). Recode of patient age stratified by level of clinical significance of error shows that errors affecting this age group represented $7.89 \%$ of the total errors. Out of this $1.37 \%$ were considered major. Eerrors affecting age group above 60 years of age represented $21.91 \%$ with $8.90 \%$ of them considered as major errors (Table 3).

Table 4 shows medications commonly affected by CGDLEs stratified by the level of clinical significance of error. Errors classified to be major represented $38.69 \%$ of the total errors and commonly associated with immunosuppressants (tacrolimus capsule and Ciclosporin capsule) and cytotoxics/anti-rheumatics (Methotrexate injection/tablet). Errors considered as moderate represented $28.77 \%$ and commonly associated 


\begin{tabular}{|l|l|}
\hline $\begin{array}{l}\text { Table 1: Risk matrix definitions for the clinical } \\
\text { significance of CGDLEs and their potential impact on } \\
\text { patient.* }\end{array}$ \\
\hline $\begin{array}{l}\text { Significance } \\
\text { of the error }\end{array}$ & Potential implication on patient \\
\hline Major & May contribute to patient fatality or potential end organ damage \\
\hline Moderate & $\begin{array}{l}\text { May cause moderate harm that needs hospitalization or } \\
\text { emergency treatment }\end{array}$ \\
\hline Minor & $\begin{array}{l}\text { May cause minor harm that do not need hospitalization or } \\
\text { emergency treatment }\end{array}$ \\
\hline None & There is error but no obvious harm \\
\hline
\end{tabular}

${ }^{*}$ Adopted from reference 7

\begin{tabular}{|l|l|l|}
\hline Table 2: Patients' demographic data (N=169). \\
\hline Description & $\mathbf{n}$ & $\%$ \\
\hline Gender & 121 & 71.60 \\
\hline Female & 48 & 28.40 \\
Male & \multicolumn{2}{|l|}{} \\
\hline Age category (years, M+SD=36.4+24.3) & 14 & 08.28 \\
\hline $02-02$ & 35 & 20.75 \\
$03-18$ & 44 & 26.04 \\
$19-40$ & 40 & 23.67 \\
$41-60$ & 36 & 21.30 \\
$61-97$ & & \\
\hline
\end{tabular}

Table 3: Recode of patients age stratified by level of clinical significance of error $(\mathbf{N}=\mathbf{2 9 2})$.

\begin{tabular}{|c|c|c|c|c|c|c|c|c|}
\hline \multirow{3}{*}{$\begin{array}{l}\text { Age groups } \\
\text { (years) } \\
\text { (\% total errors) }\end{array}$} & \multicolumn{8}{|c|}{ Levels of significance of error } \\
\hline & \multicolumn{2}{|c|}{$\begin{array}{l}\text { Major } \\
(n=113)\end{array}$} & \multicolumn{2}{|c|}{$\begin{array}{l}\text { Moderate } \\
(n=84)\end{array}$} & \multicolumn{2}{|c|}{$\begin{array}{l}\text { Minor } \\
(n=73)\end{array}$} & \multicolumn{2}{|c|}{ None $(n-22)$} \\
\hline & $\mathbf{n}$ & $\%$ & $\mathbf{n}$ & $\%$ & $\mathbf{n}$ & $\%$ & $\mathbf{n}$ & $\%$ \\
\hline 0.2 to $2(07.89)$ & 4 & 1.37 & 4 & 1.37 & 7 & 2.39 & 8 & 2.74 \\
\hline 3 to 18 (20.89) & 23 & 7.87 & 23 & 7.87 & 12 & 4.11 & 3 & 1.03 \\
\hline 19 to $40(25.68)$ & 29 & 9.93 & 21 & 7.19 & 21 & 7.19 & 4 & 1.37 \\
\hline 41 to $60(23.63)$ & 31 & 10.61 & 18 & 6.16 & 17 & 5.82 & 3 & 1.03 \\
\hline 61 to 97 (21.91) & 26 & 8.90 & 18 & 6.16 & 16 & 5.48 & 4 & 1.37 \\
\hline
\end{tabular}

with asthma medications (budesonide + formoterol) and antimicrobials (cotrimoxazole tab/suspension). The minor level of clinical significance represented $25.00 \%$ and commonly associated folic acid tablet and vitamin D3 capsule.

We identified medications like erythropoietin injection, sodium chloride injection and pancreatic granule were commonly associated with the major errors involving age group $\leq 2$ years, while medication like tacrolimus capsule, etanercept injection and ciclosporin capsule were commonly associated with the major errors involving age group of $>60$ years of age. Sergey Zakharov et al. studied the types and reasons arising from medication errors in general, for 11 years. They found that $60.46 \%$ of errors involved children below 5 years of age. The most frequent medication errors involved medications affecting the nervous system (psycho-leptics and anti-epileptics), antibiotics and medications affecting the respiratory system specially in patients over 60 years of age. They concluded that there are two high risk categories, children $<5$ years of age and geriatrics with chronic medications, therefore, risk reduction measures should focus primarily on these two categories. ${ }^{[13]}$

\begin{tabular}{|c|c|c|}
\hline Level of Significance and medications involved & $\mathbf{n}$ & $\%$ \\
\hline Major & 113 & 38.69 \\
\hline Tacrolimus capsule & 20 & 17.69 \\
\hline Methotrexate cap/injection & 19 & 16.81 \\
\hline Ciclosporin capsule & 17 & 15.4 \\
\hline Adalimumab injection & 14 & 12.38 \\
\hline Etanercept injection & 12 & 10.62 \\
\hline Erythropoietin injection & 8 & 7.08 \\
\hline Mycophenolate capsule & 7 & 6.19 \\
\hline Sodium chloride $0.9 \%$ injection & 3 & 2.65 \\
\hline Moderate & 84 & 28.77 \\
\hline Budesonide + formoterol & 10 & 11.90 \\
\hline Cotrimoxazole tab/suspension & 7 & 8.33 \\
\hline Adalimumab injection & 6 & 7.14 \\
\hline Dornase Alfa nebules & 4 & 4.76 \\
\hline Minor & 73 & 25.00 \\
\hline Folic tab & 11 & 15.06 \\
\hline VitD3 cap & 10 & 13.69 \\
\hline Tiotropium & 5 & 6.84 \\
\hline None & 22 & 7.54 \\
\hline Hydrocortisone cream & 5 & 22.73 \\
\hline Clotrimazole cream & 2 & 9.09 \\
\hline
\end{tabular}

CGDLEs associated with instructions for use comprised $29.45 \%$ of the total errors and included medications like adalimumab injection, methotrexate injection, ciclosporin capsule and syrup, tacrolimus capsule, erythropoietin injection and sodium $0.9 \%$ injection. Davis et al in their cross-sectional survey involving 251 primary care patients studied the comprehension of drug label by patients and reported that slightly more than half of patients misinterpreted common instructions. ${ }^{[14]}$

Errors associated with drug dose in this study represented $19.86 \%$ of the total errors and commonly associated with medications like ciclosporin capsule and tacrolimus capsule. The frequency of drug use errors comprised 10.96\% and commonly associated with budesonide + formoterol for inhalation, ciclosporin capsule/solution, dornase for inhalation and thyroxine tablets. The duration of therapy errors comprised $34.59 \%$ of the total errors and commonly associated with medications like methotrexate tablets, adalimumab injection, erythropoietin injection and etanercept injection. Yin et al. studied comprehension of label instructions on 287 parents or caregivers of children prescribed a liquid medication. They concluded that parents using teaspoons or tablespoons to measure the dose were more likely to make errors compared with those who used milliliter-based instruments. ${ }^{[15]}$ Another study by Davis et al. found that only $71 \%$ of educated consumers can interpret the statements 'take two tablets twice daily' correctly. Clear statements such as 'take two tablets in the morning and take two tablets in the evening' can ease the understanding of the instructions. Confusing instructions such as 'use as directed' are not preferred and should not be used unless accompanied with the maximum frequency per day. ${ }^{[16]}$

Our labels are printed in English with Arabic translation, as Arabic is the mother language of most of our patients. Therefore, errors may occur due to inappropriate translation. Translation researchers and practitioners agree 


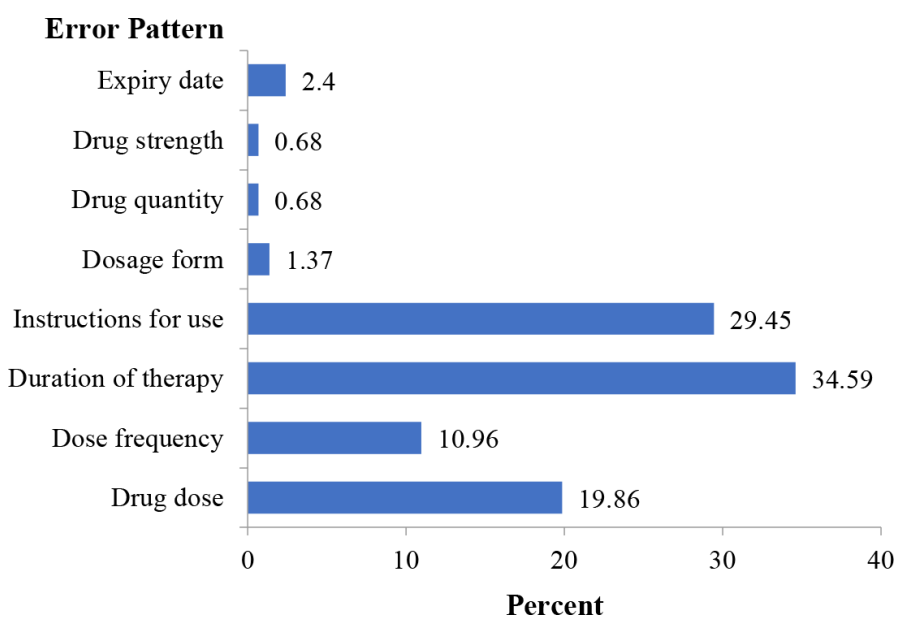

Figure 1: Patterns of computer-generated drug label errors $(\mathrm{N}=292)$.

that effective translation needs more than just replacing each word in English text with a similar word in another language. Therefore, translators should accurately evaluate the intended purpose of the original English text and determine how the same purpose can be conveyed in another language. ${ }^{[17-18]}$

Our results show that $95.27 \%$ of the identified CGDLEs were captured and corrected in station $\mathrm{B}$ where picking of medication and sticking of computer-generated label is done; the rest was captured in station $\mathrm{C}$ during delivery of medication to patients. Fortunately, all these errors were captured before reaching patients. We believe the reason behind that is the application of safety culture in the department including counterchecking. The Mean time taken to correct an error was $1.68 \mathrm{~min}(\mathrm{M} \pm \mathrm{SD}=1.68 \pm 1.23)$ and the maximum time taken for error correction was 9 minutes. After identifying the error, the pharmacist manually does the correction in English and Arabic before delivering medication to the patient. The ccorrection is done by using a new hand-written label in place of the erratic one. Verbal instructions were also conveyed to the patient to confirm the correction.

Our study showed that CGGLs could represent a source of considerable errors where some of these errors could be life-threatening. The nature of these errors may include mix-up between drug format, inappropriate use of metric units (dosing instruction was in $\mathrm{mg}$ rather than milliliter), wrong or missing frequencies and duration mismatch between English and Arabic instructions. The following case reports may illustrate some examples of computer-generated drug label errors detected in in our study:

Case 1: A 50-year-old man, post total thyroidectomy prescribed thyroxin tablets as 75 microgram 2 timed daily for 90 days. The drug was dispensed as tablets of 25 micrograms. The label says "take 3 tablets daily for 30 days". The Arabic translation says the same.

Case 2: A 4-year-old child with cystic fibrosis prescribed dornase $(1 \mathrm{mg} /$ $\mathrm{ml}$ ) for inhalation. The dose was $1.5 \mathrm{mg}$ once daily. The label says "inhale $1 \frac{1}{2} \mathrm{mg}$ once daily". No further instruction on how to administer the drug and for how long. No Arabic translation.

Case 3: A 7-year-old child with asthma prescribed sodium chloride $0.9 \%$ ampule to be added to budesonide in the nebulizer twice daily. The label says "inject $3 \mathrm{ml}$ twice daily". No more instructions for use. Arabic translation says the same.
Case 4: A 48-year-old lady with renal transplantation prescribed ciclosporin (among other 12 medications) in split dose as $75 \mathrm{mg}$ morning and $50 \mathrm{mg}$ evening. The label says "take $75 \mathrm{mg}$ in the morning". The evening dose is missing. Arabic translation says the same.

Case 5: A 47-year-old patient with rheumatoid arthritis was prescribed adalimumab as $40 \mathrm{mg}$ to be injected once every 2 weeks for 12 weeks. The label says "inject $40 \mathrm{mg}$ weekly for 4 days". Arabic translation says the same.

Case 6: A 34-year-old patient, post renal transplantation, was prescribed darbepoetin alfa injection as 40 microgram per week for 5 weeks. The label says' inject 40 microgram every week for 1 week". Arabic translation says "inject 40 microgram every week for 1 day".

Case 7: A 4-year-old child prescribed tacrolimus syrup, $1.5 \mathrm{ml}$ twice daily (to be adjusted according to the drug level in the blood) for 90 days. The label says "take $1 \frac{1}{2} \mathrm{ml}$ twice daily for 31 days". Arabic translation says the same. No instructions about drug monitoring in the label.

Case 8: A 10-year-old child with asthma was prescribed tiotropium rotacapsule as 18 microgram to be inhaled once daily. The label says "inhale 18 microgram daily in English and Arabic. No instruction for use.

Case 9: A 5-year-old child was prescribed hydrocortisone cream $0.1 \%$ to be applied sparingly twice daily for one Week. The instructions in English and Arabic on the label says "apply 1\% twice daily" and no duration stated.

Case 10: A 48-year-old patient with rheumatoid arthritis was prescribed methotrexate $20 \mathrm{mg}$ tablet on Friday with folic acid $5 \mathrm{mg}$ tablet on Saturday to be taken for 4 weeks. Methotrexate was available as $2.5 \mathrm{mg}$ tablets. Label for methotrexate says "take 8 tablets daily for 4.285714228571422857142 2857142". Arabic translation says the same. No instructions on 'when these medications should be administered'.

Optimal patient outcomes could be provided only if instructions on the drug label used as intended. This may highlight the importance of drug labels in ensuring safe and effective use of prescription and non-prescription medications. If the patient is unable to identify his medication or understand the instructions for use printed on the label, the effort made in developing the label is useless. Pharmacists and IT experts are challenged to work together to ensure that computer-generated labels prevent harm to patients while supporting the quality use of medications. Staff training and system monitoring are also required to minimize technology-related medication errors.

\section{Limitations}

In fact, we focused only on direct causes of computer-generated drug label errors and we didn't perform a root cause analysis of these errors or evaluate the possible faults in the system, hence, there may be other causes of in addition to those explained in this study. Also, this study was done in one hospital and therefore, findings may not be generalized. Finally, our findings should be interpreted carefully as they were based only on the identified and captured errors.

\section{CONCLUSION}

A clinically significant amount of computer-generated drug label errors was observed. Most of these errors were serious and can directly affect the wellbeing of patients. Fortunately, these potential errors were captured before reaching the patient. Critical evaluation and correction of the system 
that generates such labels is required. These findings emphasize the need to further assess how to best communicate drug-related information to patients using a well-designed computer-generated drug labels.

\section{ACKNOWLEDGEMENT}

We do appreciate the work of the members of senior clinical pharmacist panel who reviewed and classified the CGDLEs.

\section{CONFLICT OF INTEREST}

The authors declare no conflict of interest.

\section{ABBREVIATIONS}

None.

\section{REFERENCES}

1. Srivastava B, Prakash C, Sinha AK, Gaur S, Prasad MK. Errors in drug labeling and medico-legal awareness. J Indian Acad Forensic Med. 2011;32(3):228-30.

2. Brady AM, Malone AM, Fleming S. A literature review of the individual and systems factors that contribute to medication errors in nursing practice. J Nurs Manag. 2009;17(6):679-97.

3. Kaushal R, Barker KN, Bates DW. How can information technology improve patient safety and reduce medication errors in children's health care?. Archives Pedia Adolescent Med. 2001;155(9):1002-7.

4. Samaranayake NR, Cheung STD, Chui WCM, Cheung BMY. Technology-related medication errors in a tertiary hospital: a 5-year analysis of reported medication incidents. Int Med Informatics. 2012;81(12):828-33.

5. Walsh KE, Adams WG, Bauchner H, Vinci RJ, Chessare JB, Cooper MR et al. Medication errors related to computerized order entry for children. Pediatrics. 2006;118(5):1872-9.

6. Koppel R, Metlay JP, Cohen A, Abaluck B, Localio AR, Kimmel SE, et al. Role of computerized physician order entry systems in facilitating medication errors. Jama. 2005;293(10):1197-203.

7. AS/NZS 4360:1999 Risk Management and HB 142:1999 A Basic Introduction to Managing Risk. Available from: http://www.dtic.mil/dtic/tr/fulltext/u2/a434592.pdf.

8. Nanji KC, Rothschild JM, Salzberg C, Keohane CA, Zigmont K, Devita J, et al. Errors associated with outpatient computerized prescribing systems. J Am Med Informatics Asso. 2011;18(6):767-73.

9. Shrank W, Avorn J, Rolon C, Shekelle P. The Effect of content and format of prescription drug labels on readability, understanding and medication use: a Systematic Review. Ann Pharmacother. 2007;41(5):783-801.

10. Ngoh LN. Health literacy: a barrier to pharmacist-patient communication and medication adherence. J Am Pharm Associa. 2009;49(5):e132-49.

11. Institute of Medicine. Preventing Medication Errors. Washington, DC: National Academies Press. 2006.

12. Institute of Medicine. Health Literacy: A Prescription to End Confusion. Washington, DC: National Academies Press. 2004.

13. Zakharov S, Tomas N, Pelclova D. Medication errors-an enduring problem for children and elderly patients. Upsala J Med Sci. 2012;117(3):309-17.

14. Davis TC, Wolf MS, Bass PF III, et al. Literacy and misunderstanding prescription drug labels. Ann Intern Med. 2006;145:887(12)-94.

15. Yin HS, Dreyer BP, Moreira HA, Schaick LV, Rodriguez L, Boettger S, et al. Liquid medication dosing errors in children: role of provider counseling strategies. Academic Pediatrics. 2014;14(3):262-70.

16. Davis TC, Federman AD, Bass PF, Jackson RH, Middlebrooks MM, Parker RM, et al. Improving patient understanding of prescription drug label instructions. J Gen Internal Med. 2009;24(1):57-62.

17. Bailey SC, Sarkar U, Chen AH, Schillinger D, Wolf MS. Evaluation of language concordant, patient-centered drug label instructions. J Gen Intern Med. 2012;27(12):1707-13.

18. Bailey SC, Pandit AU, Curtis L, Wolf MS. Availability of Spanish prescription labels: a multi-state pharmacy survey. Medical Care. 2009:47(6):707-10.

Cite this article as: Abusham AA, AIRawahi HR. Analysis of Computer-Generated Drug Label Errors in a Tertiary Care Hospital. J Pharm Pract Community Med. 2018;4(3):150-4. 